\title{
Wear and Contact Temperature on Steel Surface in Linear Dry Friction Contact with Polimers with SGF
}

\author{
Dorin Rus ${ }^{1}$ and Lucian Capitanu ${ }^{2}$ \\ 1. Mechanical Department, Technical University of Civil Engineering, Bucharest 050153, Romania \\ 2. Tribology Department, Institute of Solid Mechanics of the Romanian, Bucharest 010141, Romania
}

\begin{abstract}
In this paper, we tried to present a qualitative correlation, based on extensive experimental trials between the value and the evolution of the friction coefficient, wear and contact temperature in the case of linear dry contact, thermoplastic material reinforced with SGF (short glass fibres) and various steel surfaces. We tried, believing successfully, the graphic illustration of the evolution of the steel surface wear and of the contact temperature, depending on the friction coefficient. It was analyzed in detail the influence of the normal load and sliding speed, but also of the metallic surface roughness on the friction coefficient.
\end{abstract}

Key words: Friction coefficient evolution, wear of steel surface, contact temperature, plastic material transfer, hardness of steel surface influence.

\section{Introduction}

Composite thermoplastic materials are biphasic materials consisting of a mass of polymer and the reinforcement embedded in it. The polymer provides the compressive strength of the material, while the reinforcement improves the tensile strength. Homogeneity of the material and its cohesion has an important role in obtaining some good mechanical characteristics. Thus, the disposal of the reinforcement considerable influences the tensile strength feature. Also the elasticity of the polymer can improve the compression resistance or bending resistance of the reinforcement material. The role of the basic polymer is first of all mechanical and is to provide the bond with the reinforcement fibres. It is the one that transmits the efforts between the reinforcement fibres. Therefore, it is necessary to ensure a minimum adhesion between these two phases. The adhesion cannot be achieved by mechanical means, is necessary to achieve a chemical bond for the polymer coating with the basic polymer. The treatments performed for this purpose are specific

Corresponding author: Dorin Rus, Ph.D. Eng., research fields: tribology, composite materials, and mechatronics engineering. to each thermoplastic material. Basic polymer acts as a bridge between the reinforcement glass fibres. If the binder is slightly deformable, the fibres cannot move, so only a small number of them support loading.

The polymer must allow a balanced distribution of efforts between the reinforcement fibres, but in the same time must limit their movement to prevent an excessive deformation of the product. Also, the basic polymer ensures the tightness against humidity, because most of the reinforcement fibres have a high affinity for water, resulting in the loss of some of the properties. The glass nature has importance on the time constancy of mechanical, electrical and chemical properties of reinforced thermoplastic material. In order to obtain stable products alkali-free glass is used, because all of the fibres with a high content of $\mathrm{Na}$ or $\mathrm{K}$ have characteristics that decrease rapidly in time, as a result of their superficial hydrolysis by the action of humidity. In order to improve the mechanical properties, in particular elastic modulus, glasses containing metal oxides are used in certain proportions.

The glass fibres used to reinforce the thermoplastic materials, when they are free of defects, have a minimum tensile strength of $25 \mathrm{MPa}$, and with their 
usual surface defects achieve maximum $15 \mathrm{MPa}$, although the glass itself has a resistance of 0.5-0.6 MPa. Elastic modulus achieves 750-790 MPa. Fibres have elongations of $2-3 \%$, total elastic elongation. No permanent deformations occur before breaking and no hysteresis at normal temperature.

Also, the presence of the glass fibres leads to reduction of the factor time in the creeping process. Dimensional changes due to water absorption remain a problem of hygroscopy, polymers inherent. By incorporating glass fibres in the thermoplastic materials their mechanical properties are preserved, in a wide temperature range.

Thermoplastic materials with glass fibres structurally present a mechanical association of glass and polymer fibres. Thermoplastic compounds are characterized by high plasticity under certain conditions of temperature and by their returning to the initial stage by cooling. In the plastic stage they can be processed into finished products.

Ever since the year 1964 Bowdon and Tabor [1] experimentally found that the values of the friction coefficients of the "clean" metals couplings on plastic materials and in the presence of some moderate loads are similar to those of the plastic material/plastic material friction couplings. They considered that the shear force is due to friction of the micro-junctions formed on the contact surface of the two semi couples.

In the specialty literature, there are works which give values of the friction coefficient of plastic material/metal, plastic material/plastic material, reinforced or unreinforced couplings, operating both under dry friction and in the presence of lubricants. Jacobi [2] presents for polyamide reinforced with glass fibres, values of the friction coefficient ranging between 0.04 and 0.5. Bilik [3] determined for the friction coefficient of the polyamides/steel, values up to 2.0. All the mentioned works emphasize the fact that the value of friction coefficient is not constant, it depends on the relative sliding speed, contact pressure, surface roughness, temperature, etc.
Clerico [4] studying the friction behavior of the polyamide/metal coupling found that the friction coefficient values are higher for short periods of operation, than for long term operation of the coupling. He indicates friction coefficient values from 0.1 up to 0.65 for the first three hours of coupling's operation, values that decrease up to 0.42 in the next 67 operation hours. He explains this by the viscoelastic properties of the polymer. Hrusciov and Babicev [5, 6] show the growth of micro-cutting component of the friction force for plastic material reinforced with glass fibre/steel couplings, with increasing the polymer content.

Bely et al. [7], Bartenev and Laventiev [8] studied the influence of the polymer's nature and of the glass fibres orientation in its mass, on the friction coefficient. They found that the friction coefficient values increase when glass fibres have not the same orientation in the basic polymer. Watanabe et al [9] show the increase of the friction coefficient with the increase of the normal load. They explain the influence of temperature on the friction coefficient value's decrease by the intensification of plastic material transfer to the steel. Lancaster [10] taking care of the friction behaviour of the polymers reinforced with different natures fibres, established the dependence of the friction coefficient of the ratio $\eta v d^{3} / N$ for lubricated couplings beak (of diameter $d$ )/disc type. He found the decrease of the friction coefficient with the reduction of the metallic surfaces roughness and with the increase of the mentioned report value. The friction coefficient decreases from 0.19 to 0.04 when the ratio $\eta v d^{3} / N$ increases from $10^{-14}$ to $10^{-11} \mathrm{~cm}^{2} / \mathrm{N}$, for a roughness of $0.15 \mu \mathrm{m}$ of the steel surface. For roughness of $0.46 \mu \mathrm{m}$, the friction coefficient is constant when the mentioned report increases from $10^{-14}$ to $10^{-11} \mathrm{~cm}^{2} / \mathrm{N}$.

Studying the friction behavior of the thermoplastic materials, Barlow [11] provides for friction coefficient of these on steel, values of $0.1 / 0.28$, in the presence of a lubricant. He notes the increase in the value of friction coefficient with the increase of the relative sliding 
speed between the surfaces of friction torque. West [12] examining the friction behaviour of the polyethylene/steel coupling shows the reduction of the friction coefficient from 1.24 to 0.78 , when the normal load increases from 10 to $5,000 \mathrm{~N}$. He demonstrates that for normal loads of $250(1,500 \mathrm{~N}$, the friction force is proportional to the factor $\left(N^{0,88}\right)$, and the friction coefficient is proportional to $\left(N^{0,22}\right)$.

Bartenev et al [13] establish in the case of plastic materials friction on metallic surfaces, the increase of friction force with increasing the logarithm of sliding speed. This dependence is expressed by Vinogradov, for friction on metals of crystalline polymers. In the case of adhesion processes preponderance, he finds also an increase of the friction force with the normal load.

From the above, it can be concluded that the friction process of thermoplastic materials is extremely complex, a variety of parameters influencing the value of the force and of the friction coefficient. These parameters, physical and mechanical, influence the friction process in the presence of a lubricant in the contact region, and in the absence thereof. Although relatively numerous, the published works do not allow a complete characterization of the process, due to the heterogeneity of the materials tested and the experimental conditions used as well as of the contact types variety and of the research installations used.

If realized researches and published works on the friction behaviour of the thermoplastic material reinforced with glass fibres/metal coupling are quite numerous, not the same can be said about those published in the wear domain. The data presented in the specialty literature concerning the wear of this coupling, refer to certain limited domains of use of the reinforced thermoplastic materials. Most papers treat qualitative aspects of the wear phenomenon, just few presenting and its qualitative side. Thus, Bowden and Tabor [14] have highlighted the importance of the distribution of stresses on the contact surface, showing that in the case of a Hertzian contact with a pressures elliptical distribution, the central area of the contact surface will be more seriously damaged than the marginal areas due to higher values of surface tensile stresses $(\mu p)$ and reach to exceed a certain critical value $(\mu p)_{c}$.

Jost [15] highlights that for the polyamide/metal coupling adhesion wear predominates both in the dry friction conditions and in the presence of the lubricant.

Lancaster and Evans [16] studying the wear behaviour of reinforced polymers under hydrodynamic lubrication, observed the decrease in wear rate with increasing the value of the factor $\eta v d^{3} / N$ for beak type couplings with diameter $(d)$, made of plastic material, in friction on metal discs. The decrease is more pronounced, as the metal surface roughness is more reduced. He set for polyamide (PA) $+\mathrm{MoS}_{2} /$ steel coupling $\left(R_{a}=0.15 \mu \mathrm{m}\right)$, the wear rate of $5 \times 10^{-6}$ $\mathrm{mm}^{3} / \mathrm{Nm}$ and for the $(\mathrm{PA})+$ graphite/ steel coupling $\left(R_{\mathrm{a}}\right.$ $=0.15 \mu \mathrm{m})$, the wear rate of $5 \times 10^{-7} \mathrm{~mm}^{3} / \mathrm{Nm}$, while for the $(\mathrm{PA})+$ glass $/$ steel couple $\left(R_{\mathrm{a}}=0.15 \mu \mathrm{m}\right)$ the wear rate reaches $4 \times 10^{-4} \mathrm{~mm}^{3} / \mathrm{Nm}$, and $3 \times 10^{-6}$ $\mathrm{mm}^{3} / \mathrm{Nm}$ for $(\mathrm{PA}) /$ steel couple $\left(R_{\mathrm{a}}=0.15 \mu \mathrm{m}\right)$.

Shen and Dumbleton [17] comparatively studying the wear behavior of high density polyethylene and polyoxymethylene (Delrin 150 commercial type), processed by injection, establish for the wear coefficient values from 7.8 to $28.6 \times 10^{-10} \mathrm{~cm}^{2} / \mathrm{N}$. They propose to calculate the linear wear of high density polyethylene (UHMWPE), a relation of the type:

$$
h=k p x
$$

where, $h$-linear wear; $k$-wear factor; $p$-nominal pressure; $x$-sliding distance.

Based on the above relation, they have established for the wear factor of high-density polyethylene, values ranging from $1.3-3 \times 10^{-11} \mathrm{~cm}^{2} / \mathrm{N}$.

Capitanu et al $[18,19]$ reported about the behavior of polyamide and polycarbonate reinforced with glass fibres in friction on steel surfaces. Capitanu and Florescu [19] presented some tribological aspects of the steel surfaces wear in dry friction with polymer composites with glass fibres. 


\section{Materials and Methods}

Friction and wear processes were analyzed for a relatively wide range of tribological parameter values that affect it (load, relative speed, temperature). Range of values used for the parameters mentioned include both values commonly encountered in industrial applications, as well as some extreme values, less common, but that are of interest from the point of view of the friction and wear mechanism. Thus, although the values of the stresses and the speeds some parts made of thermoplastic materials usually work are between 0.2-1 MPa and respectively $1-500 \mathrm{~cm} / \mathrm{s}$, attempts were made at speeds and loads greater than or less than the ranges mentioned.

The two elements of friction couplings (cylindrical sleeve and flat sample) were made of plastic material and metal, respectively. The metallic elements of the examined couplings were made of steels of different qualities and with different surface states. Of tested steels only a few qualities widely used in industrial practice have been selected for presentation.

For friction and wear tests polyamides and polycarbonates were selected from the wide range of thermoplastic materials processed in industry, in view of their increased reinforcing possibilities with glass fibres and high density polyethylene because of its use as a replacement of metals in some practical applications. Experimental tests have been conducted using polyamides and polyesters reinforced with $20 \%$ and $30 \%$ of glass fibres. For comparison, friction-wear tests were performed and with unreinforced polyamides and polycarbonates.

For the experimental tests have been used thermoplastic materials whose characteristics are presented in Ref. [19]. A certain variation of such characteristics according to the various commercial types is observed, variation which occurs in rather limited ranges. From Ref. [19], it is noted that the improvement of physico-mechanical properties of materials reinforced with glass fibres, compared to the unreinforced ones.
Nylonplast AVE Polyamide [20] has incorporated $30 \%$ glass fibres having a diameter of $12 \mu \mathrm{m}$, resulting in an accentuated decrease of products deformation. Thus, at $50{ }^{\circ} \mathrm{C}$ and a compression of $140 \mathrm{daN} / \mathrm{cm}^{2}$, deformation decreases from $1.4 \%$ in the case of unreinforced polyamide to $0.2 \%$ for the reinforced one. Noryl Polyamide [21], reinforced with $20 \%$ glass fibres is characterized by a very low water absorption and high value of elastic modulus. Lexan Polycarbonate [22], reinforced with $20 \%$ glass fibres, has a high mechanical strength, a very good dimensional stability, and high resistance to shock. Makrolon polycarbonate [23], unreinforced, has high resistance to shock, outstanding dimensional stability, low water absorption and low deformability. Technyl Polyamide [24], although unreinforced with glass fibre, presents due to its high capacity of crystallization, a high consistency of mechanical properties, low deformability, good resistance to bending, strength and shock, a good friction resistance. Fig. 1 shows a series of photomicrographs intended to restore some details on the structure of thermoplastic materials tested.

Friction and wear behaviour of the materials above, considered significant for the polyamides and polycarbonates tribological manifestation, has been studied and will be presented in detail in this paper.

Fig. 1a shows the microstructure of Nylonplast AVE Polyamide reinforced with $30 \%$ glass fibres with a diameter of approximately $12 \mu \mathrm{m}$ [20]. Fig. $1 \mathrm{~b}$ presents a cross-section from a dent of a gear wheel manufactured through injection from Nylonplast AVE Polyamide $+30 \%$ glass fibres [20]. Fig. 1c shows the image of a cross section for a sample made of Noryl Polyamide $+20 \%$ glass fibres [21]. Fig. $1 \mathrm{~d}$ renders the image of the microstructure of Lexan Polycarbonate reinforced with $20 \%$ glass fibres of approximately 8 $\mu \mathrm{m}$ diameter [22], and Fig. 1e shows a cross section of the dent of a gear wheel manufactured from Lexan polycarbonate reinforced with glass fibre [23]. Fig. If shows the image seen in polarized light of the microstructure of non-reinforced Technyl polyamide. 


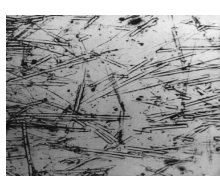

$\mathrm{a}(\mathrm{x} 70)$

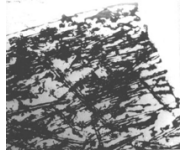

$\mathrm{d}(\mathrm{x} 70)$

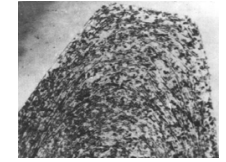

$\mathrm{b}(\mathrm{x} 50)$

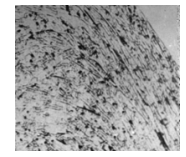

e (x60)

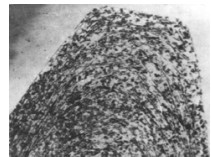

$\mathrm{c}(\mathrm{x} 70)$

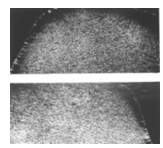

$\mathrm{f}(\mathrm{x} 100)$
Fig. 1 Microphotographs of the structures of thermoplastic materials reinforced with glass fibers, submitted to friction and wear tests: (a) Nylonplast AVE Polyamide $+30 \%$ glass fibers; (b) an image of the cross section from a dent of a gear wheel manufactured through injection from Nylonplast AVE Polyamide $+\mathbf{3 0} \%$ glass fibers; (c) the image of a cross section from a sample made of Noryl Polyamide $+20 \%$ glass fibers; (d) image of the microstructure of Lexan Polycarbonate reinforced with $\mathbf{2 0} \%$ glass fibers of approx. 8 $\mu \mathrm{m}$ diameter; (e) a cross section of the dent of a gear wheel manufactured from Lexan polycarbonate reinforced with glass; (f) image seen in polarized light of the microstructure of non-reinforced Technyl polyamide [19].

Metallic contraparts of tribological tested couples were made of the following steels: C 120 steel hardened 59 HRC; Rp3 steel, hardened $62 \mathrm{HRC}$ and 33 MoC 11 steel hardened 51 HRC. The mechanical characteristics, chemical compositions and some microstructure considerations of these steels are given in Ref. [18].

The surfaces of metal samples were processed by grinding, wet polishing with aluminium oxide and polishing with diamond paste for different grain sizes.

This technology has allowed to obtain surfaces with $R_{\mathrm{a}}=0.025 \mu \mathrm{m}, R_{\mathrm{a}}=0.045 \mu \mathrm{m}, R_{\mathrm{a}}=0.075 \mu \mathrm{m}$ and $R_{\mathrm{a}}=0.125 \mu \mathrm{m}$. For the experiments, samples with roughness higher or lower than the one mentioned above were used, for a more complete characterization of the friction and wear process.

Due to the wide range of loads and speeds considered, and the need to achieve the greatest possible variety of working conditions (contact pressures, sliding speeds and temperatures) for a more complete characterization of the tribological behavior of composite material/steel coupling was used an experimental installation with Timken type friction torque (with linear contact). This can achieve very high contact pressures (between 16 and $36 \mathrm{MPa}$ ). Testing installation has been presented in detail elsewhere [19].

\section{Results and Discussions}

Tests carried out have had the purpose of determining the influence of the main factors affecting the friction in the case of thermoplastic material reinforced with glass fibres/metal couplings. It is well known the law established by Coulomb (1780) that the friction force $F_{\mathrm{f}}$ is direct proportional to the normal force $N$ :

$$
F_{\mathrm{f}}=\mu N
$$

More studies conducted later have shown that $\mu$, the friction coefficient, is not only dependent on the normal force. Relations for variations of the friction force, depending on the load applied can be considered, of the form:

or more simply:

$$
F_{\mathrm{f}}=a N+b N^{\mathrm{n}}
$$$$
\text { or more simply: }
$$

$$
F_{\mathrm{f}}=a+b N
$$

or:

$$
F_{\mathrm{f}}=a+b N^{\mathrm{n}}
$$

Last relationships lead to the conclusion that when the normal force is equal to 0 , the friction force has other value than $0\left(F_{\mathrm{f}}=\mathrm{a}\right)$. Although this could be explained by the presence of a remanent force of adhesion of the two surfaces, even after the removal of the normal load, however, we consider more accurate the use of a relationship of the form:

$$
F_{\mathrm{f}}=k N^{\mathrm{n}}
$$

where, $n$ is subunitary.

Friction coefficient, according to Coulomb's Law, has the expression (of Eq. (1)), $\mu=F_{\mathrm{f}} / N$. We can express the friction coefficient for the plastic materials and in the following form:

$$
\mu=\tau / p_{\mathrm{c}}
$$

where, $\tau_{\mathrm{f}}$ represents the shear strength of the softer material, and $p_{\mathrm{c}}$ represents the flow pressure of the same material.

Because $p_{\mathrm{c}}=H B / 3$, results:

$$
\mu=3 \tau_{\mathrm{f}} / H B
$$


Eq. (7) is in agreement with the experimental preliminary results.

Increasing the friction coefficient increases the wear rate, but no one managed to establish a mathematical relation between the two quantities, although this is widely recognized. In the following, we shall give some suggestive graphical representations that make a qualitative correlation between the two quantities, and tying them to the contact temperature.

The influence of load on the friction coefficient of the Nylonplast AVE PA + 30\% glass fibres/C120 steel coupling is shown in Fig. 2 for Timken type coupling (with linear contact), at the sliding speed of $18.56 \mathrm{~cm} / \mathrm{s}$. It can be seen the increase of the friction coefficient of with the increase of normal load applied to the coupling. The variation of friction coefficient is nonlinear, in accordance with Eq. (5).

At this sliding speed, the dry friction coefficient on C120 steel has values between 0.27 and 0.37 , the contact temperature ranging between 108 and $165^{\circ} \mathrm{C}$. In the case of friction on Rp3 steel, dry friction coefficient values (Fig. 3) are between 0.25 and 0.38 , the contact temperature ranging between $78{ }^{\circ} \mathrm{C}$ and $155^{\circ} \mathrm{C}$.

At the onset of frictional process (temperature around $100{ }^{\circ} \mathrm{C}$ ), glass fibres are ripped from the array of plastic and expelled on the surface of steel with plastified polymer (left).

Around the contact temperature of $140{ }^{\circ} \mathrm{C}$ the transfer of the polymer occurs on the output of all of the wear (center), at a temperature of $160{ }^{\circ} \mathrm{C}$ to protect the cross-bridges of polymer (right) who interrupt the direct contact of the composite sample with a metallic surface.

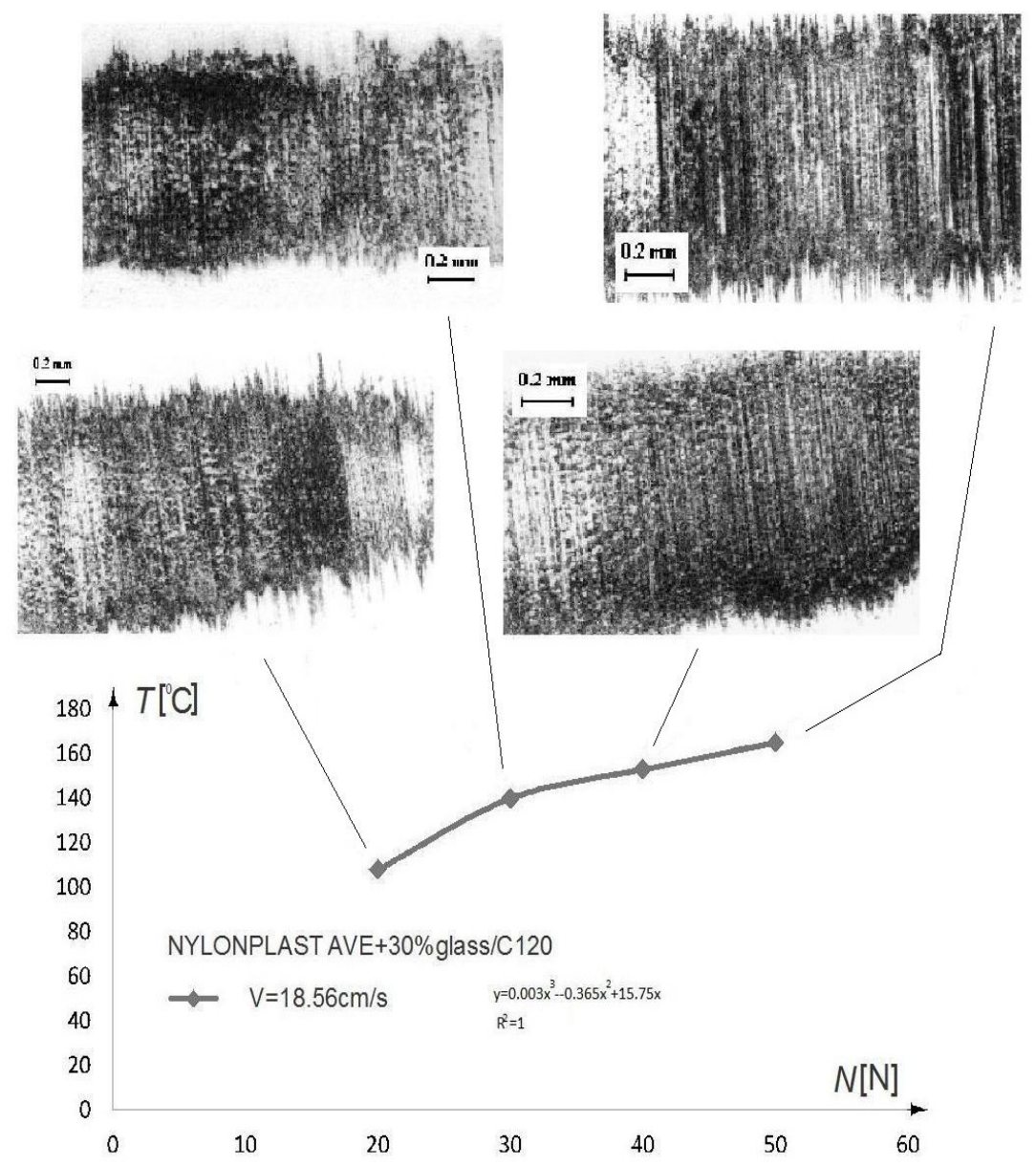

Fig. 2 Variation contact temperature function of the normal load at the sliding speed of $18.56 \mathrm{~cm} / \mathrm{s}$ for Nylonplast AVE PA + $30 \%$ SGF/C120 steel. 


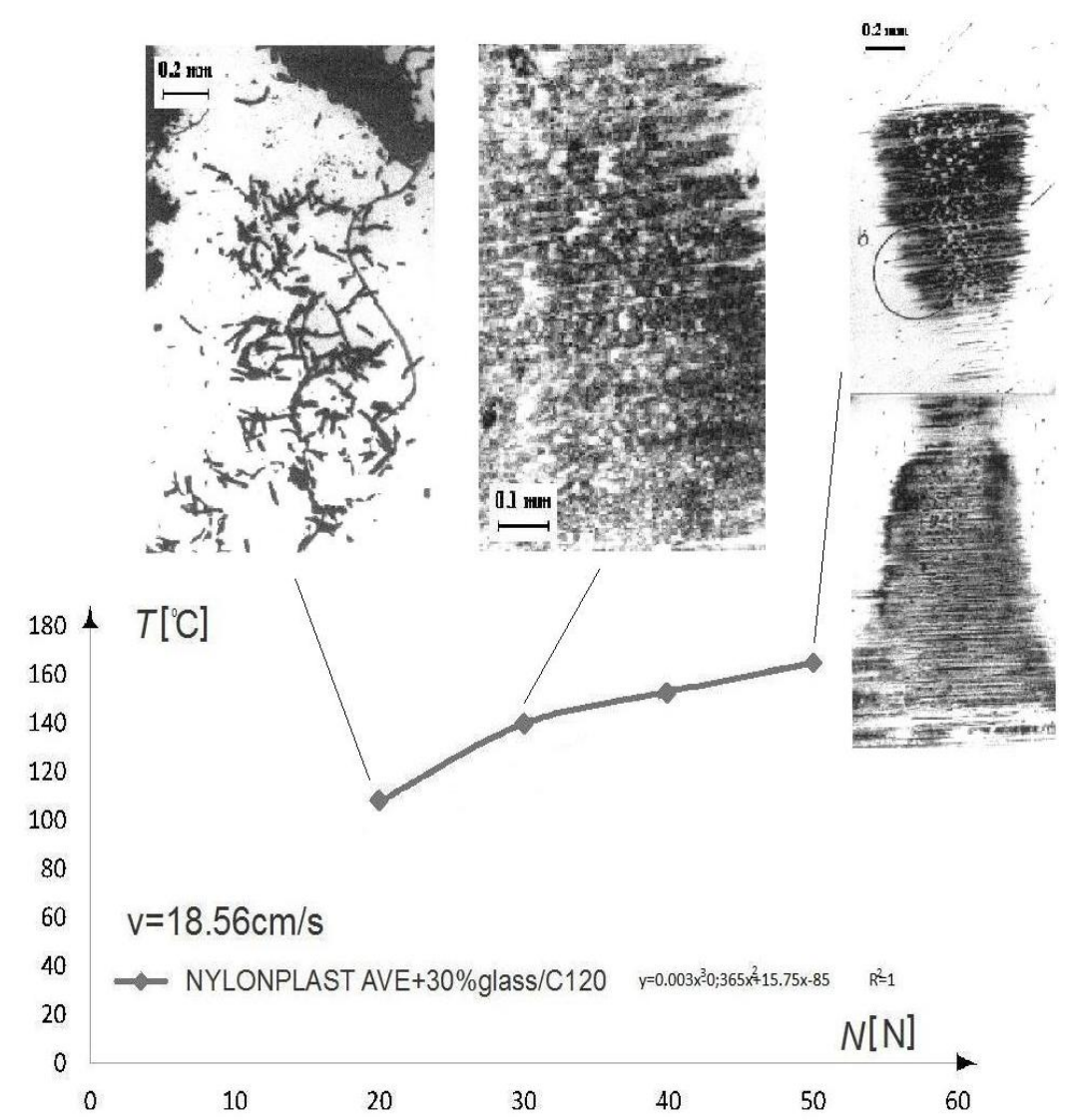

Fig. 3 The variation of wear mode depending of the contact temperature and normal load, at speed sliding of $18.56 \mathrm{~cm} / \mathrm{s}$ for PA AVE Nylonplast 30\% SGF/C120 steel.

In the case of friction on steel Rp3, dry friction coefficient values (Fig. 4) are ranging between 0.25 and 0.38 , contact temperature ranging between 81 and $155^{\circ} \mathrm{C}$.

Fig. 5 shows the variation of the friction coefficient and contact temperature function of the normal load for Nylonplast AVE $+30 \%$ glass fibres/C120 steel coupling, at sliding speed of $27.85 \mathrm{~cm} / \mathrm{s}$. At this sliding speed the dry friction coefficient has values between 0.32 and 0.35 , the contact temperature ranging between 108 and $165^{\circ} \mathrm{C}$. In the case of friction on Rp3 steel, dry friction coefficient values (Fig. 4) are between 0.27 and 0.38 , the contact temperature ranging between $135^{\circ}$ and $188^{\circ} \mathrm{C}$, function of the applied normal load.

At the $37.13 \mathrm{~cm} / \mathrm{s}$ sliding speed, the feature of metallic surface wear visible change, becoming mostly abrasive, adhered material being removed and deposited on the output of wear scars (Fig. 6), begins to appear and the corrosion wear manifested through pits in the centre of wear traces.

Fig. 6 shows the traces of wear and tear after $60 \mathrm{~min}$ of testing at this speed, when the friction coefficient is between 0.37 and 0.33 , and the contact temperature is between $135^{\circ} \mathrm{C}$ and $190{ }^{\circ} \mathrm{C}$.

Fig. 7 shows the wear traces after 60 min of testing at this speed. The friction coefficient varies between 0.33 and 0.37 , and the contact temperature varies between $135^{\circ} \mathrm{C}$ and $190{ }^{\circ} \mathrm{C}$.

Evolution of contact temperature and of $\mathrm{C} 120$ steel surface wear appearance at the speed of $55.70 \mathrm{~cm} / \mathrm{s}$, for the same friction torque, is shown in Fig. 7, when the friction coefficient varies between 0.37 and 0.40 and contact temperature is between 150 and $267{ }^{\circ} \mathrm{C}$. The wear character becomes visible adhesive when the applied load increases at the value of $40 \mathrm{~N}$ (contact temperature $238^{\circ} \mathrm{C}$ ).

At the highest sliding speeds used for testing, 111.4 and $153.57 \mathrm{~cm} / \mathrm{s}$, in the case of $\mathrm{C} 120$ steel friction 


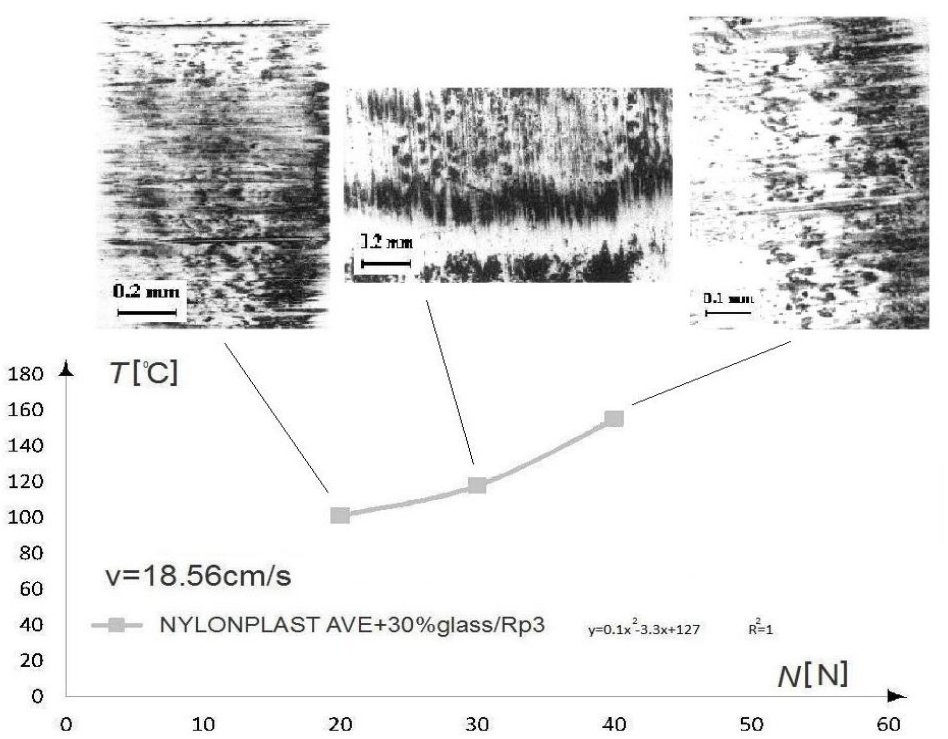

Fig. 4 Variation of the friction coefficient and contact temperature function of the normal load at sliding speed of $18.56 \mathrm{~cm} / \mathrm{s}$ for PA Nylonplast AVE + 30\% SGF/Rp 3 steel couple.

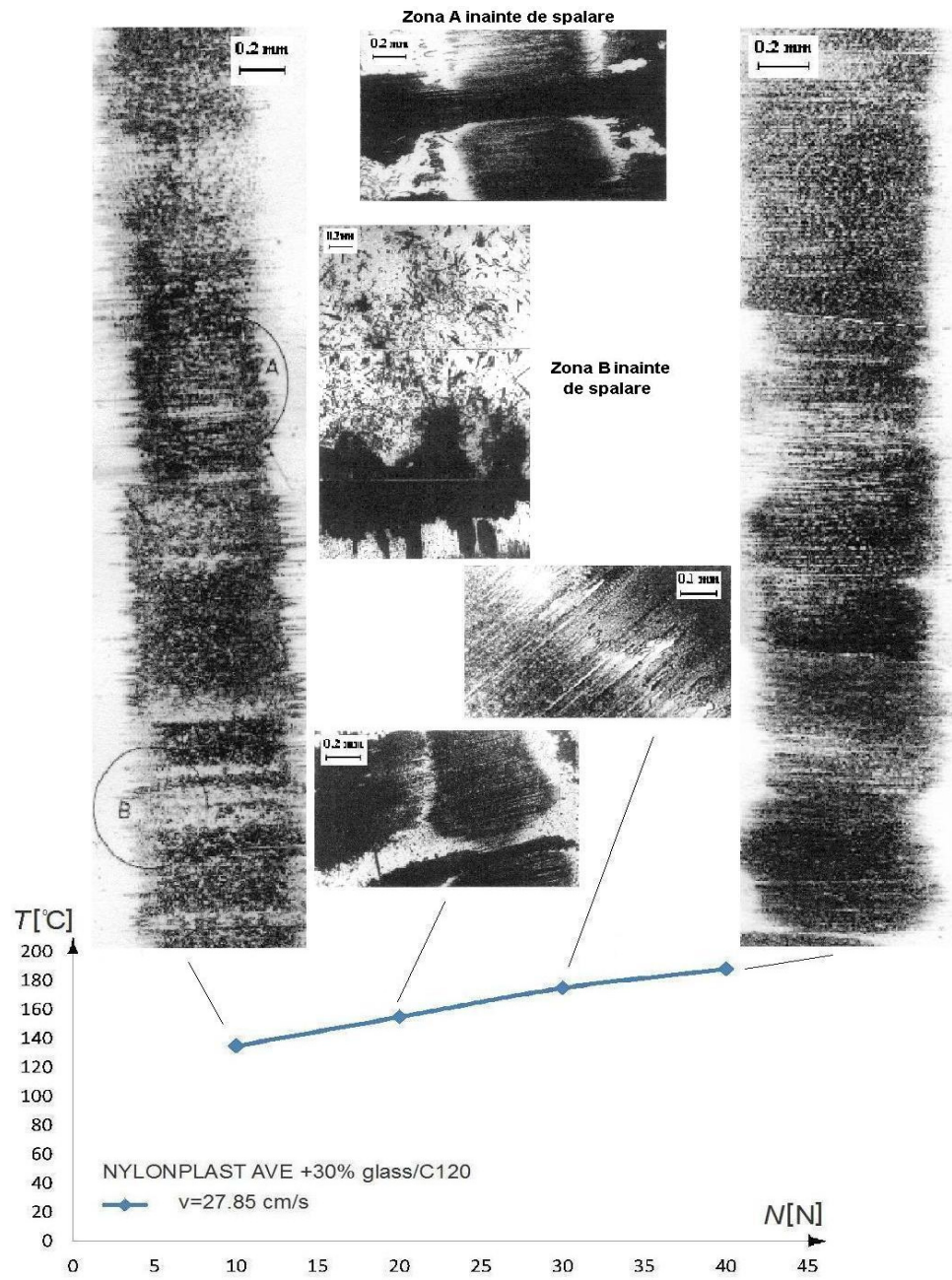

Fig. 5 Contact temperature variation based on normal load at the sliding speed of $27.85 \mathrm{~cm} / \mathrm{s}$ to Nylonplast AVE $30 \%$ SGF PA/C120 steel. 


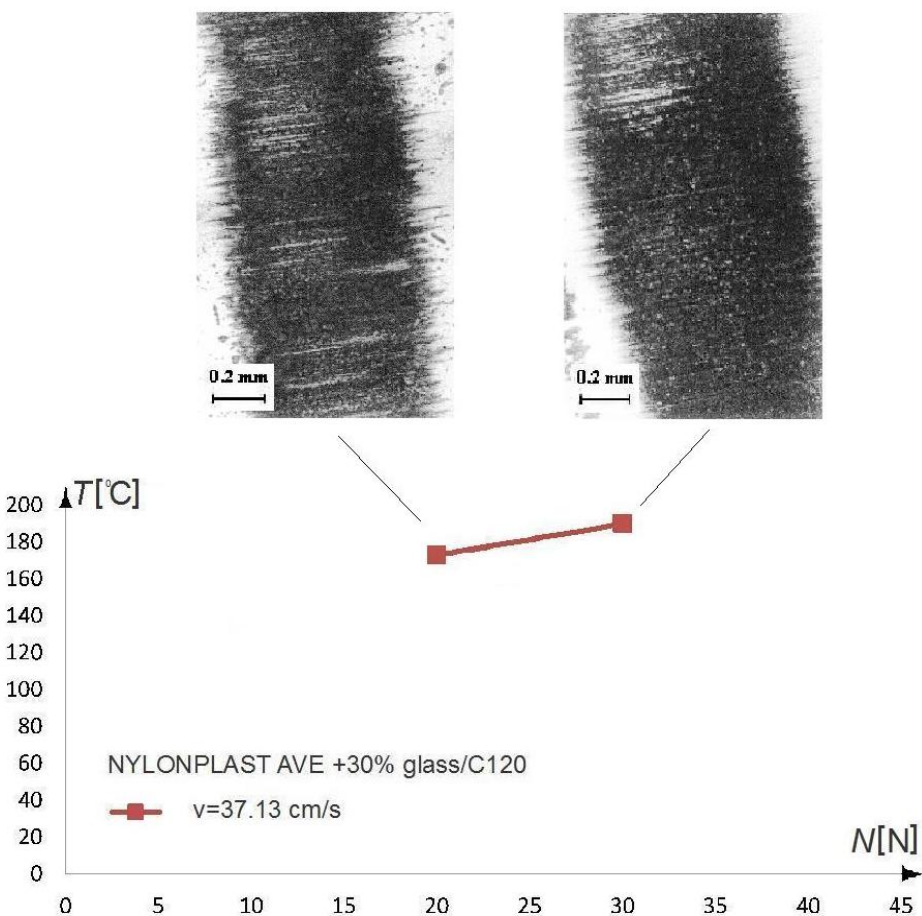

Fig. 6 Contact temperature variation based on normal load at the sliding speed of $37.13 \mathrm{~cm} / \mathrm{s}$ to Nylonplast AVE 30\% SGF PA/C120 steel.
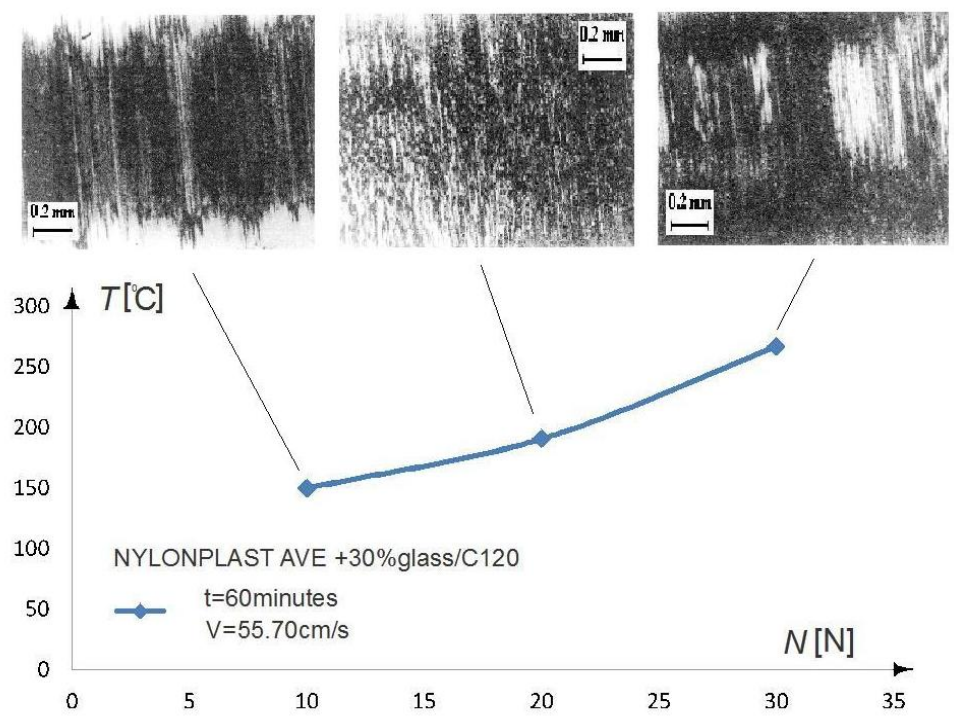

Fig. 7 Evolution of contact temperature and of $\mathrm{C120}$ steel surface wear appearance at the speed of $55.70 \mathrm{~cm} / \mathrm{s}$, for Nylonplast AVE + 30\% SGF/C120.

coefficients between 0.37 and 0.48 are reached, the measured contact temperatures ranging between 279 and $295{ }^{\circ} \mathrm{C}$ (Figs. 8 and 9). This makes the wear to manifest mainly by adhesion and corrosion.

In the case of friction of polymer with $30 \%$ glass fibres on Rp3 steel surfaces that are harder (62 HRC) up against C120 steel surfaces, can make the same findings on wear evolution function of the normal load and sliding speed as in the case of C120 steel.

Thus, under the same test conditions, the wear increases with increasing the normal load of the sliding speed, friction coefficients are somewhat lower, ranging in 0.27-0.42 domain, but the contact temperatures are between $164{ }^{\circ} \mathrm{C}$ and $249{ }^{\circ} \mathrm{C}$, in used test conditions. 


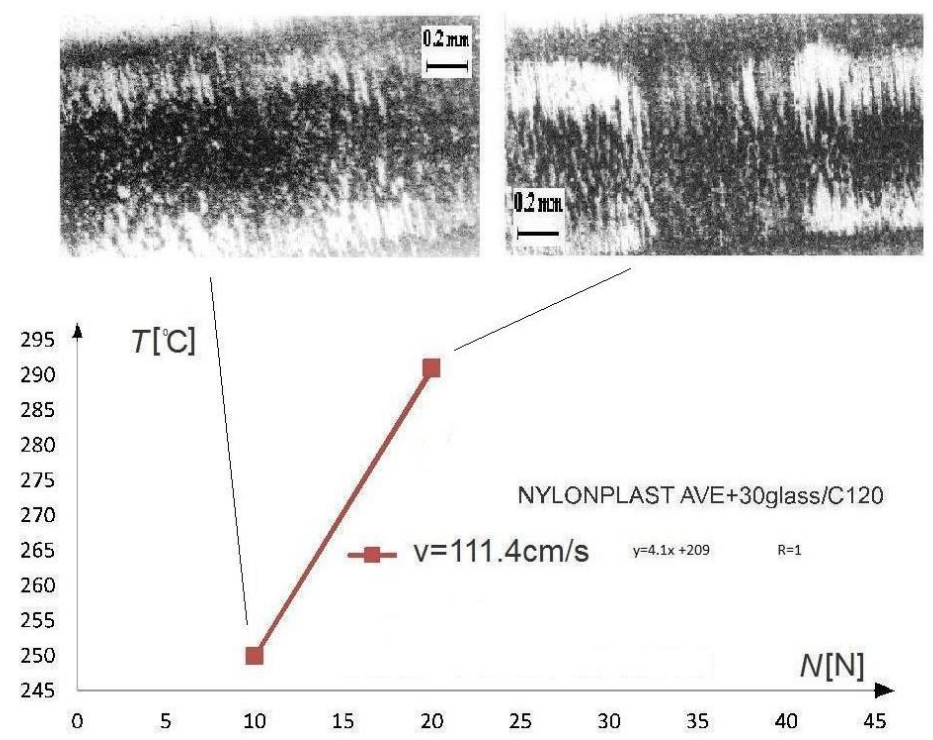

Fig. 8 Contact temperature variation based on normal load at the sliding speed of $37.13 \mathrm{~cm} / \mathrm{s}$ to Nylonplast AVE $30 \%$ SGF PA/C120 steel.

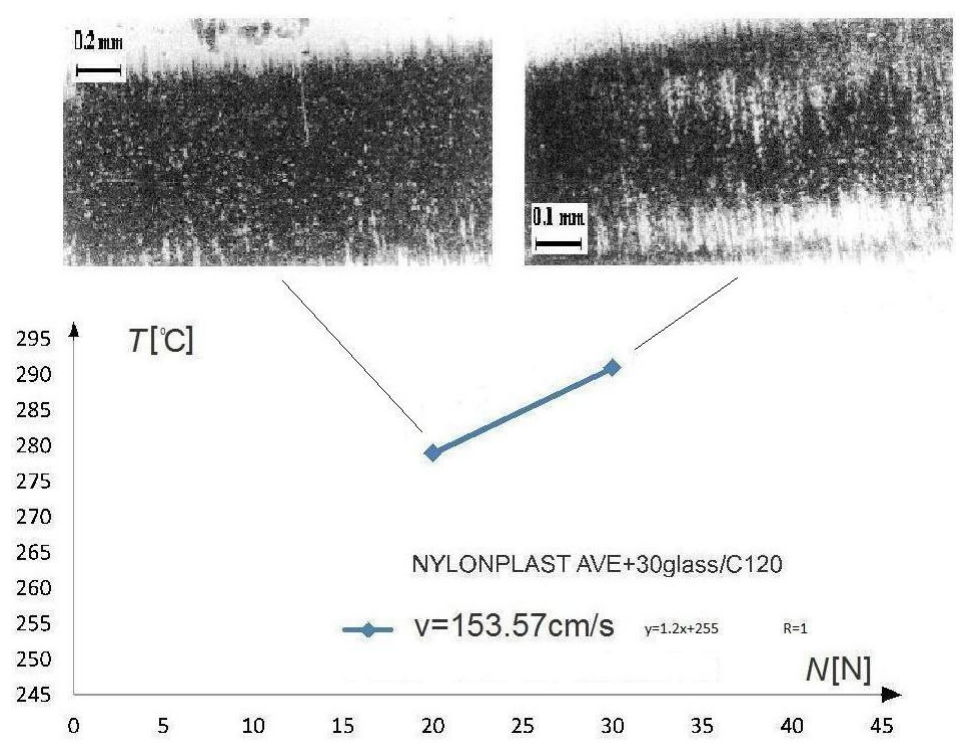

Fig. 9 Contact temperature variation based on normal load at the sliding speed of $153.57 \mathrm{~cm} / \mathrm{s}$ to Nylonplast AVE $30 \%$ SGF PA/C120 steel.

For example, Figs. 10 and 11 show the contact temperature variation function of the normal load, at the speeds of 37.13 and $46.41 \mathrm{~cm} / \mathrm{s}$, for the friction of polyamide Nylonplast AVE $+30 \%$ SGF on Rp3 steel surfaces.

For example, Fig. 12 shows the diagram of contact temperature variation and images of the phenomena described above.

With regard to the correlation between load and temperature, Table 1 presents the equations of regression and correlation factors between the two sizes, for the friction couples studied.

These relationships confirm polynomial form of the relationship between frictional force and normal load presented in relationships (2), (3) and (4).

\section{Conclusions}

From the above, we can draw several conclusions:

(1) The wear process of metallic surfaces in dry friction contact against plastic materials reinforced 


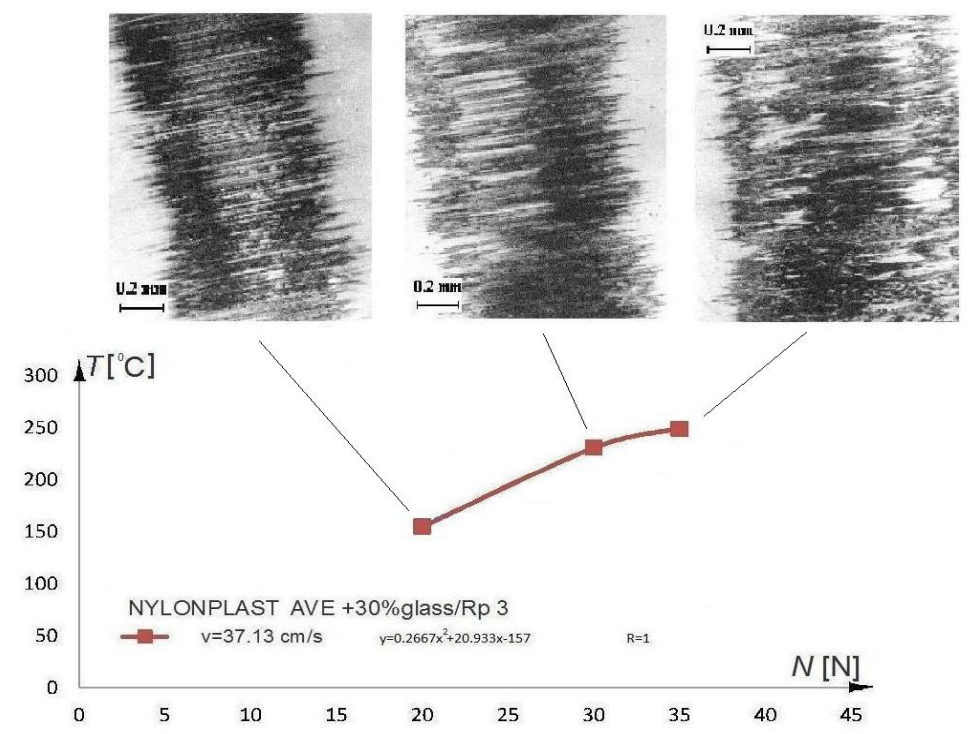

Fig. 10 Evolution of contact temperature and of steel surface wear appearance at the speeds of $37.13 \mathrm{~cm} / \mathrm{s}$ for PA Nylonplast AVE + 30\% SGF/Rp3.

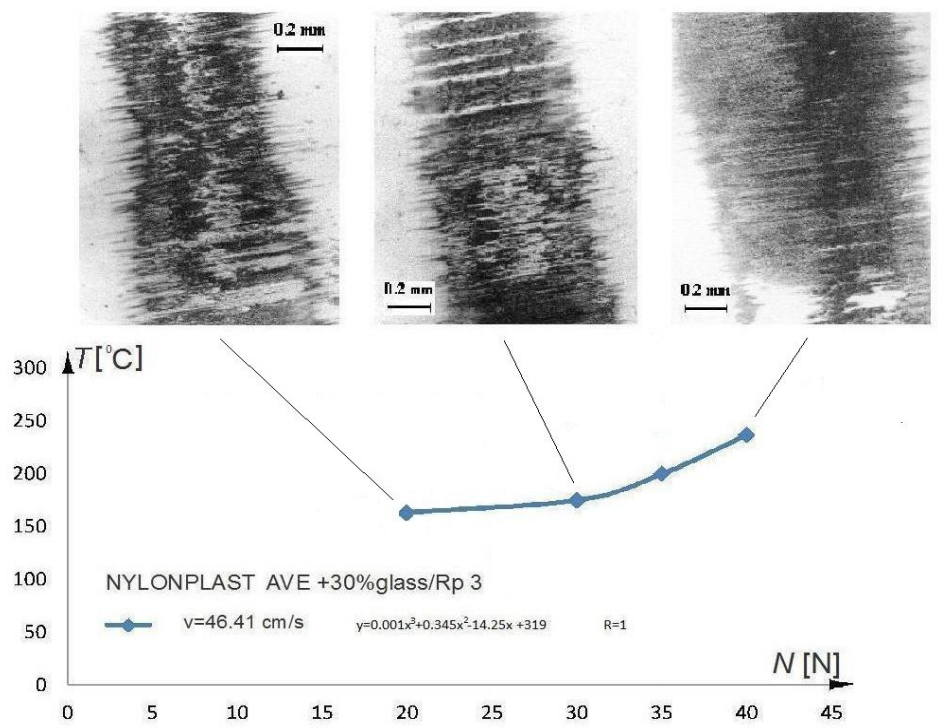

Fig. 11 Evolution of contact temperature and of steel surface wear appearance at the speeds of $46.41 \mathrm{~cm} / \mathrm{s}$ for PA Nylonplast AVE + 30\% SGF/Rp3.

with short glass fibres evolves over time, depending on loading, moving from the initial abrasive wear caused by glass fibres, at adhesion wear characterized especially by the transfer of plastic material on the metallic surface, but also by corrosion;

(2) The friction coefficient has values in a wide range comprised between 0.2 and 0.5 ;

(3) Contact temperatures increase function of the applied load and the sliding speed, reaching values of $295^{\circ} \mathrm{C}$, resulting in plasticizing of plastic material and exceeding the transition temperature at the glass and even the flow one;

(4) The friction coefficient values of the reinforced plastic materials, on the surfaces of the C120 steel samples are higher than those obtained on the surfaces of Rp3 steel samples. The explanation for this phenomenon lies in the difference in hardness of samples surfaces made of the two steels. This behavior confirms Eqs. (6) and (7). Eq. (7) is consistent with the results shown in Figs. 4, 10 and 11; 


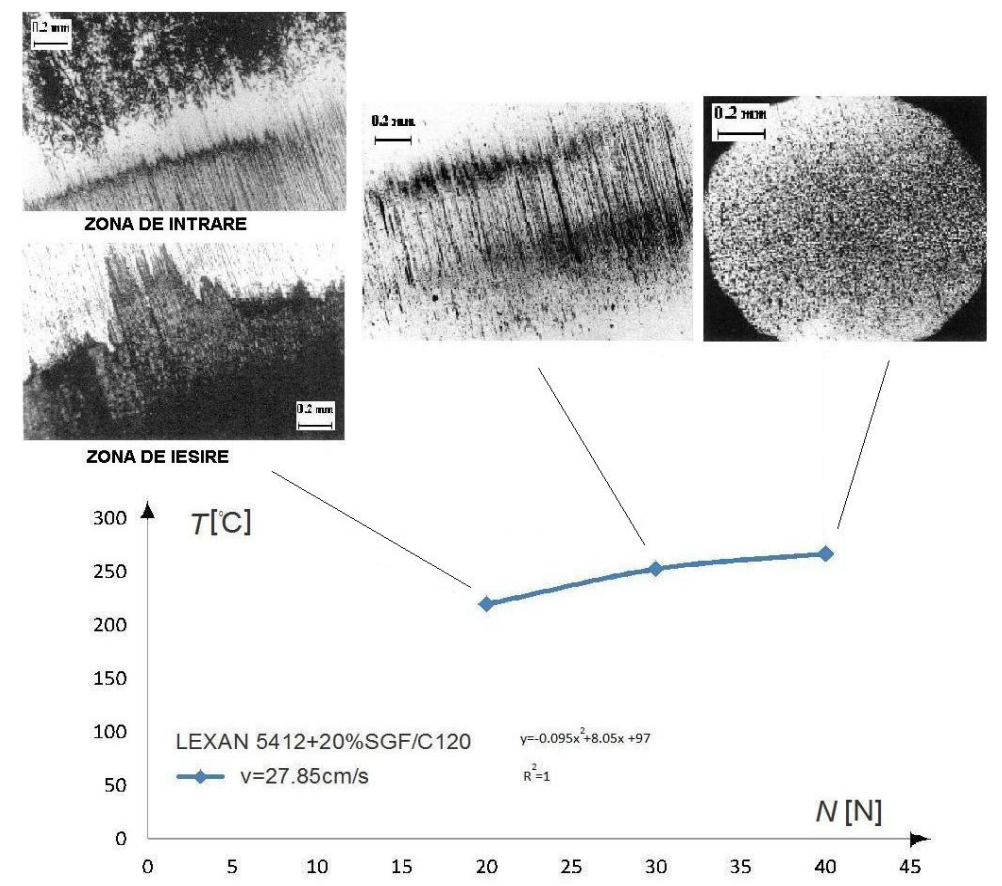

Fig. 12 Evolution of contact temperature and of steel surface wear appearance at the speed of $27.85 \mathrm{~cm} / \mathrm{s}$, for PC Lexan 3412 $+20 \%$ SGF/C120.

Table 1 Regression function of the normal load and contact temperature.

\begin{tabular}{lll}
\hline Friction couple & $v(\mathrm{~cm} / \mathrm{s})$ & Regression function \\
\hline PA + 30\% SGF/C120 steel & 18.56 & $T=0.003 N^{3}-0.365 N^{2}+15.75 N-85$ \\
PA + 30\% SGF/C120 steel & 111.4 & $T=4.1 N+209$ \\
PA + 30\% SGF/C120 steel & 153.57 & $T=1.2 N+255$ \\
PA + 30\% SGF/Rp3 steel & 18.56 & $T=0.1 N^{2}-3.3 N+127$ \\
PA + 30\% SGF/Rp3 steel & 37.13 & $T=0.2667 N^{2}+20.933 N+157$ \\
PA + 30\% SGF/Rp3 steel & 46.41 & $T=0.001 N^{3}+0.345 N^{2}+14.25 N+319$ \\
PC + 20\% SGF/C120 steel & 27.85 & $T=0.095 N^{2}+8.05 N+97$ \\
\hline
\end{tabular}

(5) Friction coefficient values on C120 steels, of the thermoplastic materials reinforced with glass fibres, pass through a minimum located in the normal loads domain of 20-30 N. In the case of the same materials friction on the Rp3 steel surfaces, the increase of the friction coefficient with normal load is quasilinear. The explanation for this phenomenon is that, under the action of the tension states, the C120 steel undergoes superficial cold hardening manifested by the increase of its hardness in the friction area. Hardening occurs at contact pressures between 1.75 and $2.0 \mathrm{MPa}$, corresponding for the linear contact couplings used for a load of $20 \mathrm{~N}$. At higher loads, respective greater efforts, the harden layer is destroyed and entails the increase of the friction coefficient as result of hardness decreasing;

(6) Although it cannot establish a mathematical relation between the friction coefficient, contact temperature and metallic surface wear, we believe that the manner of graphical presentation of the wear state of the metallic surface and the contact temperature (friction coefficient) is significant for the plastic material/steel contact.

However, this research has some limitations. Thus, at high contact temperatures, is unlikely that the elastic contact assumption in which the modeling was made, to be valid.

Also, the contact temperatures were measured at 1 
mm below the metallic contact surface, so obviously the real temperature was higher.

Evaluation of the friction coefficient was done over time as an average of the friction coefficient during the test and not as a friction coefficient at a certain time.

\section{References}

[1] Bowden, F. P., Tabor, D. 1967. Friction and Lubrication. London: Metheuen \& Co. Ltd.

[2] Jacobi, H. R. 1957. "Neue Erkenntnisse uber Gleitenschaften von Polyamiden." Kunststoffe 47 (5): 234-9.

[3] Bilik, M. 1965. Parî trenia metal-plastmassa v maşinah $i$ mechanizmah. Moskva: Izd. Maşinostroienie.

[4] Clerico, M. 1969. "A Study of the Friction Wear of Nylon against Metal.” Wear 13 (3): 183-97.

[5] Hrusciov, M. M. 1957. "Resistance of Metals to Wear by Abrasion, as Related to Hardness." Presented at the Conf. Lubr. and Wear, Inst. Mech. Eng., London.

[6] Hrusciov, M. M., and Babicev, M. A. 1958. "Resistance to Abrasive Wear of structurally Inhomogeneous Materials." Friction and Wear in Machinery 12: 5-24.

[7] Bely, V. A., Sviridenok, A.I., and Petrokovets, M. I. 1982. Friction and Wear in Polymer Based Materials. Pergamon Press.

[8] Bartenev, G. M., and Lavrentiev, V. V. 1972. Trenie $i$ Iznos polimerov. Leningrad: Izd. Himia.

[9] Watanabe, M., Korusawa, M., and Marsubara, K. 1968. "The Frictional Properties of Nylon." Wear 32 (3): 185-91.

[10] Lancaster, J. K. 1972. "Lubrication of Carbon Fibre reinforced Polymers." Wear 28 (3): 315-52.

[11] Barlow, D. A. 1972. "Some Observations of the Friction Properties of Vinyl." Wear 20 (2): 151-7.
[12] West, G. H., and Senior, J. M. 1973. "Frictional Properties of Polyethylene." Wear 19 (1): 37-52.

[13] Bartenev, G. M., Lavrentiev, V. V., and Konstantinova, N. A. 1971. "The Actual Area and Friction Properties of Elastomers under Frictional Contact with Solid Surfaces." Wear 18 (6): 439-48.

[14] Bowden, F. P., and Tabor, D. 1964. The Friction and Lubrication of Solids, Part I-II. Oxford: Clarendon Press.

[15] Jost, H. 1970. "Zum Verschleissverhalten von Polyamid." Plaste und Kautschuk 17 (4): 266-70.

[16] Lancaster, J. K., and Evans, D. C. 1979. "The Wear of Polymers." In Treatise of Mat. Sci. and Technology, edited by Scott, D. Vol. 13. New York: Academic Press, 86-140.

[17] Shen, C., and Dumbleton, J. H. 1978. "The Friction and Wear Behavior of Polyoximethylene in Convection with Joint Replacement." Wear 38 (2): 291-303.

[18] Capitanu, L., Iarovici, A., and Onisoru, J. 2003. “On Polyamide and Polycarbonate Materials Behaviour under Dry Friction." The Annals of University "Dunarea de jos" of Galati, fascicle VIII, Tribology, ISSN 1221-4590.

[19] Capitanu, L., and Florescu, V. 2013. "Tribological Aspects of Wear of Polished Steel Surfaces in Dry Friction Contact on Polymer Composites with Glass Fibres." American Journal of Materials Science 3 (1): 8-18.

[20] Nylonplast AVE Polyamide, Informazione Technica, Rhodiatace Sp.A, Milano, Aug. 1984.

[21] Le Noryl, un material technique pour l'industrie automobile, Plastique Modernes et Elastomers, 27, 3, 1975.

[22] Lexan, Polycarbonate Resin, General Electric. Product Data: February, 1969.

[23] Bayer, A. G. 1985. Makrolon-Description des types.

[24] Dorin, R. 2015. Tribological implication of linear dry contact GFR polimers on steel. Germany: Scholars' Press, ISNB-13: 978-3-639-76352-2. 